\title{
HEALTH OF THE ESTONIAN POPULATION BY OBJECTIVE AND SUBJECTIVE STATISTICS
}

\author{
ENE-MARgit TitT \\ Faculty of Mathematics and Computer Science, University of Tartu, \\ Tartu, Estonia
}

\begin{abstract}
Many studies concerning the health problems of the population have been conducted in Estonia during the last decades. In the population census of 2011, several questions about health conditions were also asked. Summarizing the subjective and objective data, it turns out that the general health situation of the Estonian population is steadily improving. During the last decade, the life expectancy of Estonian men and women has increased by approximately five years. Statistical data also show that education is strongly correlated with the health situation: people with a higher level of education have, in general, fewer health problems. The people living in rural areas have somewhat more health-caused limitations in their everyday life - the reason for this situation seems to be deficiencies in communication and conveniences.

The general health situation of a population is a very important indicator. It should be taken into account when planning social policy but also in calculating the resources of workforce in the country or estimating the costs needed for retirement allowances. The number of medical personnel also depends on the estimated health of the population, as this knowledge also works as an input for education policy
\end{abstract}

Keywords: population health, population census, statistics, Estonia

\section{DATA}

To make decisions about the health of the population, it is necessary to have data. In Estonia, many studies concerning health problems have been conducted during the last decades, and many data are available in databases. Still, some authors declare in the media that "the health of the Estonian population 
is very bad and is permanently worsening" and other authors say, "the health of the Estonian population is good nowadays and is improving."

Many data on the health condition of the Estonian population are openly available, but their use for analysis needs some knowledge about their sources and the ways how they were gathered.

\section{Census data}

Census questionnaires have included some questions about the health conditions of respondents at several times. For instance, in the very first censuses organised in Estonia in the 19th century, people were asked if they were blind, deaf or feebleminded. In the censuses organised by the Republic of Estonia in 1922 and 1934, some additional questions on physical impairments were asked. Health conditions were not asked in the censuses organised by the German occupation authorities (1941) and by the Soviet regime (1959, 1970, 1979 and 1989) [Tiit, 2011]. In the 2000 census, it was asked if the person had an officially registered disability. In the questionnaire of the population and household census of 2011, there were two questions concerning the health of the respondent: "Do you have any long-term illness or health problem?" and "Do you have limitations of everyday activities due to health problems?" All the data of the last two censuses (2000 and 2011) are available on the homepage of Statistics Estonia [Statistics Estonia].

\section{Survey data}

In Estonia, many studies concerning health have been made during the last decades. Among them, there are some local surveys organised by Estonian institutions and covering some groups of population but also internationally organised wide-scale panel research as SHARE [share] that allows comparing Estonian population and its particular groups with representatives of other countries.

The main results of these surveys are available in the database of the National Institute for Health Development [National]. The administrators of the database say the following about the database:

Health Statistics and Health Research Database is the place for publishing statistics and survey results about health and health-related issues in Estonia.

The data are gathered by the National Institute for Health Development (http://www.tai.ee/en), medical registries in the Institute, the Estonian Health Board (http://www.terviseamet.ee/en/information/about-hb.html) and other institutions. The database is constantly updated with new data. 
The database consists of seven main areas that divide into sub-areas:

- Characteristics of Population

- Morbidity

- Use of Healthcare and Reasons for Treatment

- Healthcare Resources

- Health Promoting Institutions

- Health Behaviour

- Statistics on Medicines

The tables presented in the database can be viewed in the Internet and downloaded using different file formats (.px, .xls, .dbf, .txt). (http://pxweb.tai.ee/esf/ pxweb2008/dialog/Info/TSTUA.html)

\section{Difference between census data and survey data}

Research projects are usually very exhaustive and cover the research area in depth. On the opposite, censuses contain only a few quite simple questions about health (if any). Why are these additional questions necessary at all?

There are at least two very important differences in favour of census data. One is that census covers the whole population - in the case of Estonia, about 1.3 million people. Research projects involve several thousands of people; that means in most cases less than $1 \%$ of the population. Hence, each respondent of a survey answers for more than a hundred similar people - but usually these people are not very similar. By using surveys, one can never get information about small areas and small groups of people.

The second problem is that census is mandatory by law, but answering to surveys is voluntary. Naturally, interviewers do hard work to get answers from the people who are not very happy to participate, but there is still is positive probability that several groups of people are undercovered in survey data. The future of statistical analysis in medicine is using register data.

\section{Register data and big data}

Nowadays, there is a strong tendency in statistics is to use increasingly more register data. The UN has agreed on the Millenium Development Goals Indicators, and among them, the revolution of data is also mentioned [UN]. What does this mean? Mainly the reusability of already collected data. One possibility is using data from a well-organised register, as the Health Insurance Fund, the Estonian Medical Birth Registry, the Estonian Abortion Registry, etc.

Another possibility is to use so-called big data that have been collected for different aims (in general, not for statistics), using various new statistical and IT methods as data mining, etc. 
In Estonia, there exists a number of well-organised registers containing different data useful for analysing population health; the most important among them are the data collected in the system of e-Health [e-Health]. Not all data from this developing system are already useable for researchers and medical doctors, but hopefully the application of register data will be the future of medical research.

\section{OBJECTIVE DATA CHARACTERISING THE WHOLE POPULATION: CURRENT STATISTICS AND CENSUS. DEVELOPMENT OF HEALTH OF THE ESTONIAN POPULATION DURING THE LAST DECADES}

\section{Probability of death and share of survivors}

Using the current mortality statistics and census-based population sizes, it is possible to calculate the probability of death and the share of survivors for each age group and so to construct the life table, see Figure 1.

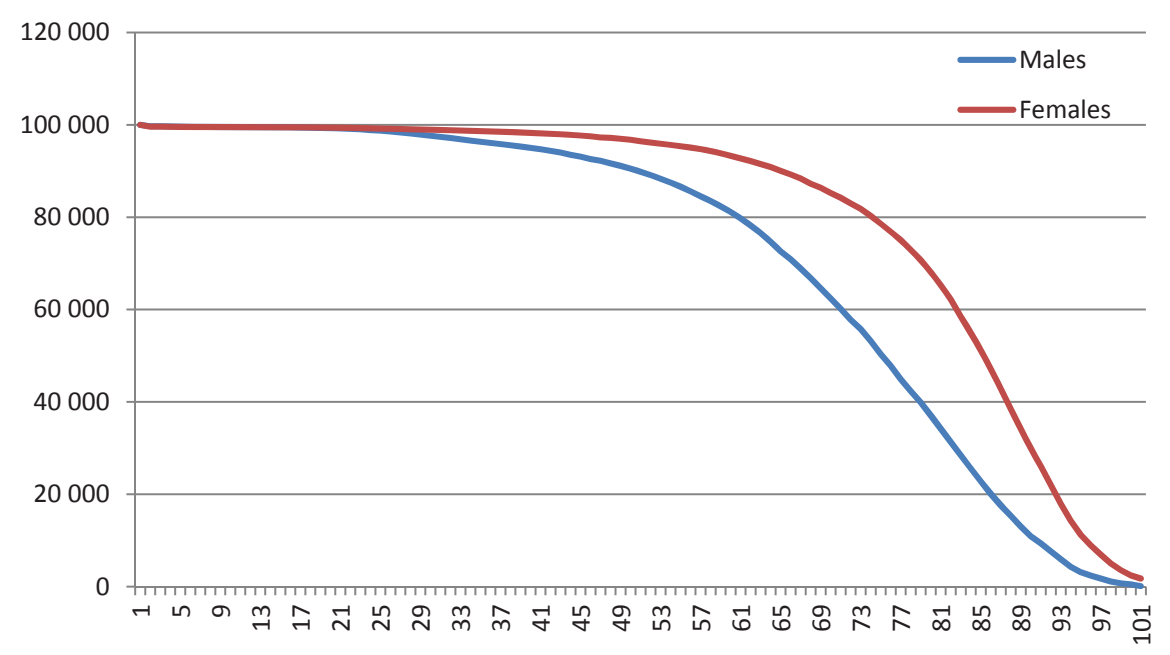

Figure 1. The life table, showing the expected number of surviving men and women from the initial generation of the size 100000 persons, 2012. Data: Statistics Estonia

\section{Trends of life expectancy}

One of the most important objective characteristics of population health is life expectancy that is calculated by the life table. This indicator has been used as one of the components in calculating a country's human development 
index (HDI) and is the main indicator for ranking the countries by the health of their populations.

Life expectancy is calculated for people of different ages, and it shows the expected life duration of people if mortality during the person's life cycle will remain the same as it is at the time of calculation. It is understandable that, in general, this condition will not be satisfied; mortality declines steadily, and so, in most cases, the actual life expectancy of real people is longer than the calculated expectancy.

Life expectancy can also be regarded a very important characteristic of population's health in a given year, and its trends characterise the development of population health in the country.

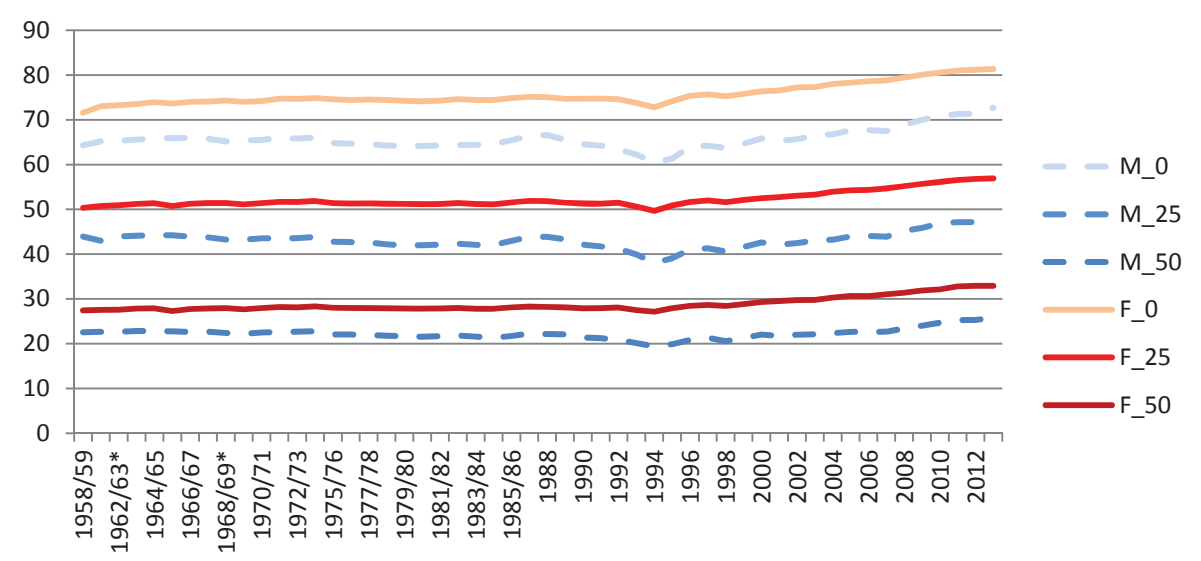

Figure 2. Changes in life expectancy (the average remaining lifetime in years for persons who attain a given age) in Estonia from 1958 to 2013 (55 years). Men and women of ages 0, 25 and 50. Data: Statistics Estonia

During the long period (55 years), the methodology of calculation has somewhat changed (from 1988, one basic year instead of two years has been used), but this fact does not influence the results.

Figure 2 shows the following features:

- In Estonia, men's life expectancy at birth is about 10 years shorter than that of women. Such a big difference is quite exceptional in the world and occurs mainly in Eastern Europe. In Estonia, the difference has an A-shaped form, starting with 7.3 years in 1958 , gaining its maximum value 11.4 years in 1994 and being 8.6 years in 2013.

- There are several periods in the development of the characteristic. From 1958 to 1988 (30 years) men's life expectancy increased by 2.3 and women's 
life expectancy by 3.4 years. The increase was not equable, especially in the case of men: during the 25 years up to 1983, life expectancy was steadily about 64 years but increased to 66.5 years in 1985-1988 (so-called Gorbachev's law of prohibition). In women, the change was more balanced.

- Life expectancy reached its lowest value in 1994 (men 60.5, women 72.8). This year all the negative trends cumulated - the number of criminal deaths was high; this was also the year of the catastrophic shipwreck of Estonia. From this year onwards, life expectancy has almost steadily increased and, by the data of 2013, was 72.7 years for men and 81.3 years for women - during 20 years, an increase of 12.2 years for men and 10.3 years for women. The growth has been especially rapid since 2000 .

- The difference between women's and men's life expectancy at different ages shows that the mortality of working-age men is higher than that of women. There is no big difference in childhood mortality; men who have reached a high age also have a probability to live for several years.

\section{Disability-free life expectancy}

Disability-free life expectancy is the average number of years that a person who attains a certain age is expected to live free of disability if the current patterns of mortality and disability continue to apply. This indicator was calculated using the census data (that cover the whole population, but are subjective), and the results are presented in Figure 3.

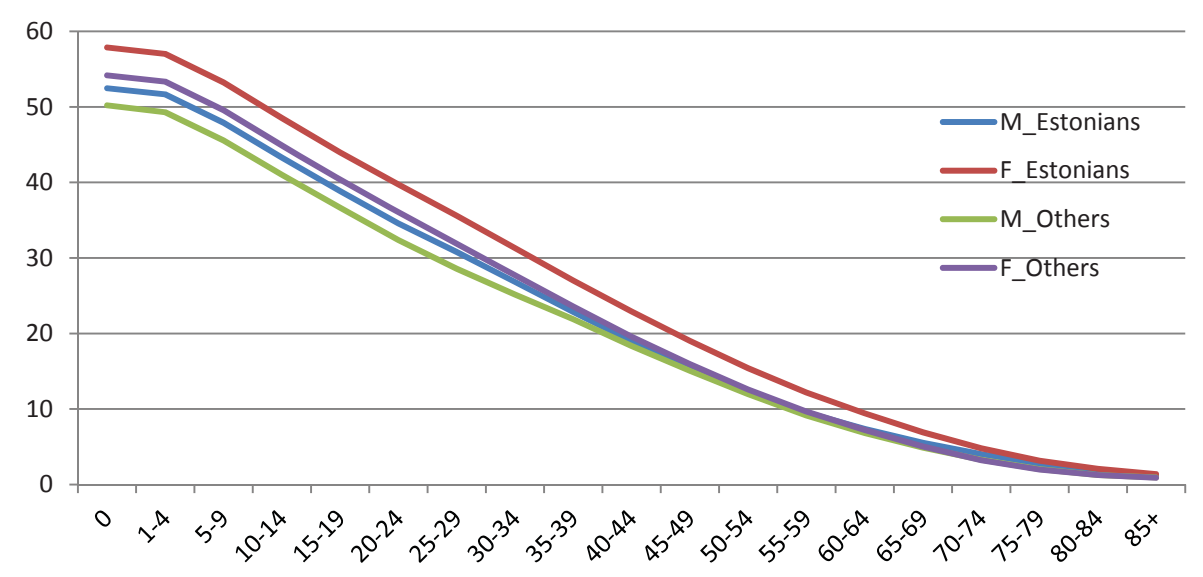

Figure 3. Disability-free life expectancy for people of different sex and age groups and ethnicities in Estonia, 2011. Data: Statistics Estonia 
We see again that for men disability-free life expectancy is shorter than for women, but the difference is not as big as it is in the case of life expectancy. As a result, we can say that in 2011 a man living in Estonia had health problems during 19.4 years, that is $27 \%$ of his full life duration. For women, the corresponding number is 24.6 years or $30.4 \%$ of the whole life duration.

\section{Education as a factor influencing the health of Estonian people}

The fact that average Estonian people have health problems during more than a quarter of their life- span is frightening. The first question is: what are the factors influencing people's health? One of them is sex. From Figure 3, it follows that ethnicity (in the sense of being Estonian) is not a risk factor - rather it is a risk factor living in Estonia but having some other ethnical background.

Analysis of census data revealed that education has a strong effect on the health of the population; see Figure 4 .

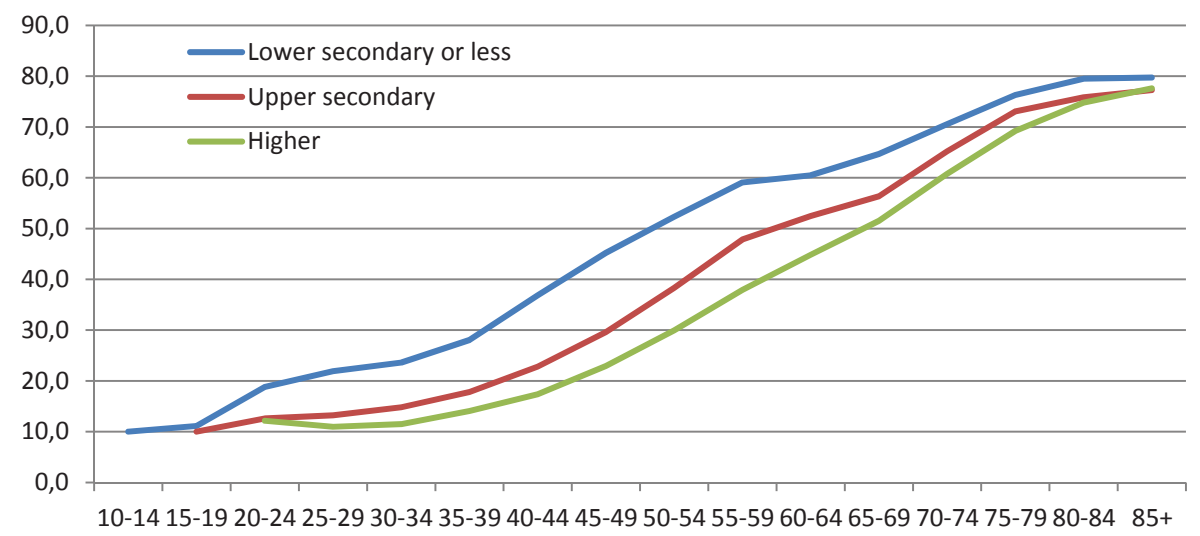

Figure 4. Share of people from different age groups and education levels having some health problems or long-lasting illnesses. Data: Statistics Estonia

From Figure 4, it follows that in age-group 25-49, i.e. in the best working age, highly educated people have twice fewer health problems than people of the same age with considerably lower education. Naturally, the impact might be mutual - people having health problems are less effective and successful in learning and getting education. But assumingly, the main reason for health problems is lifestyle that depends substantially on education and the communication environment. 


\section{Regional differences in health conditions of the Estonian population}

There also exists another factor influencing the health conditions of the Estonian population - that is the region where a person lives; see Figure 5.

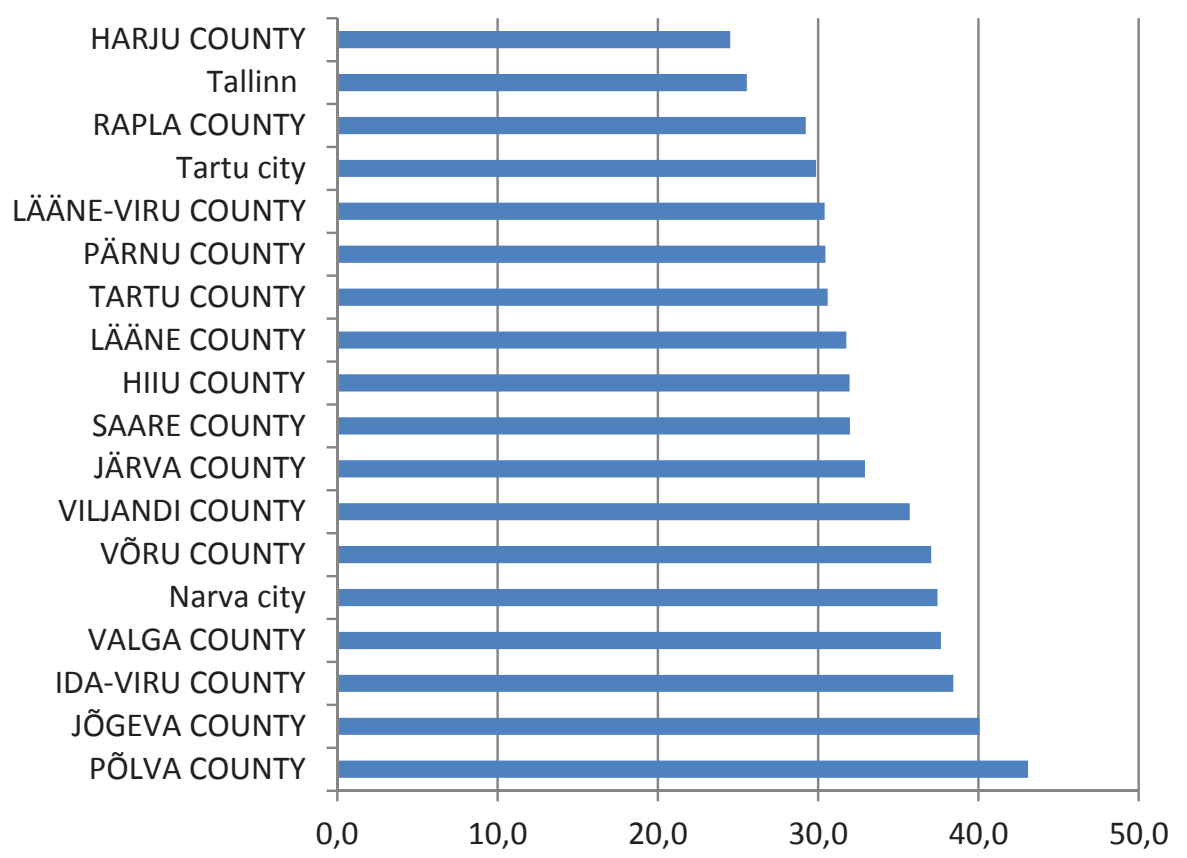

Figure 5. The percentage of people having health problems or long-term illnesses by counties and bigger cities. Data: Statistics Estonia

The differences between counties are quite big, see Figure 5: in Põlva, Jõgeva and Ida-Viru counties the share of people having health problems is $57-76 \%$ larger than in Harju county. One reason for this is that, in these counties, the average age of the population is $3.6-4.3$ years higher than in Harju county, but this is not a complete explanation. Obviously, the population feels worse in the sense of health conditions in the counties that are at a lower economic level.

\section{Limitations of everyday activities due to health problems}

The second question about health conditions asked in the census concerned limitations of everyday activities due to health problems. Here the impact of the living environment was revealed: in cities, people felt less restricted by health problems than in rural settlements; see Figure 6. The fact is quite 
understandable if we think about poorer amenities in villages and farmhouses where everyday life demands drawing water out of the well, chopping wood and heating stoves.

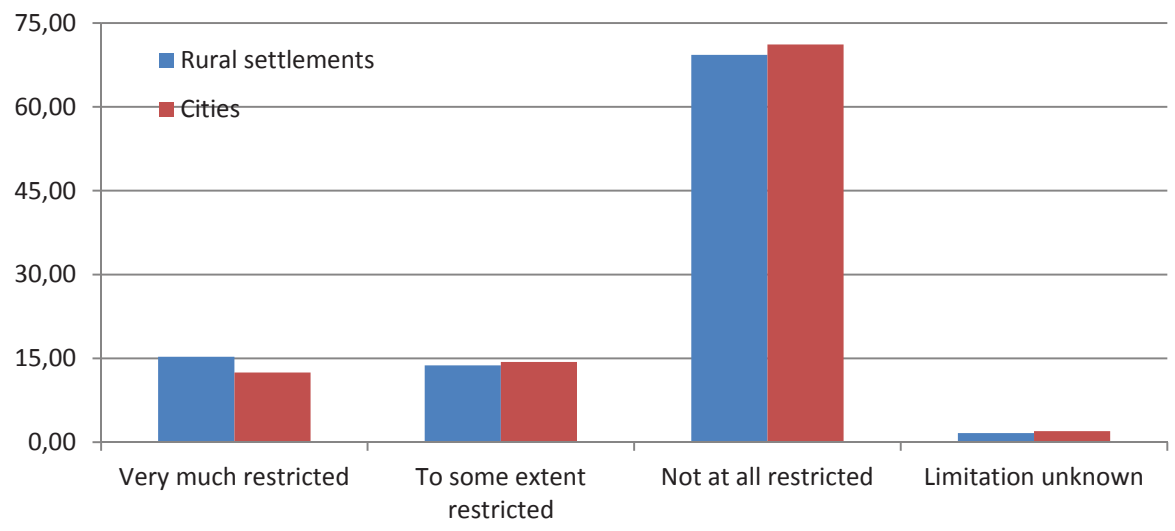

Figure 6. Limitations of everyday activities due to health problems depending on place of residence. Data: Statistics Estonia

\section{SURVEY DATA: SUBJECTIVE SELF-ASSESSMENT OF HEALTH}

The difference between census data and survey data is that survey data measure only a sample. From this fact, it follows that sample data contain a random error that is, in general, larger in the case of smaller sample size. Census data and also current statistics do not contain random (sampling) errors. In this sense, census data is more exact compared with survey data.

\section{Dynamics of self-assessment in men and women}

The database of the National Institute for Health Development contains survey data on self-assessment of health of adult persons (aged 16-64) gathered in every two years from 1990. The results of this survey are presented in Figure 6.

The most spectacular effect is that the share of people estimating their health as good or very good has increased from $23 \%$ in 1990 to more than $50 \%$ in 2014. At the same time, the share of people having bad health has not changed very much, being steadily about $10 \%$. The trends are quite similar in both sexes. 


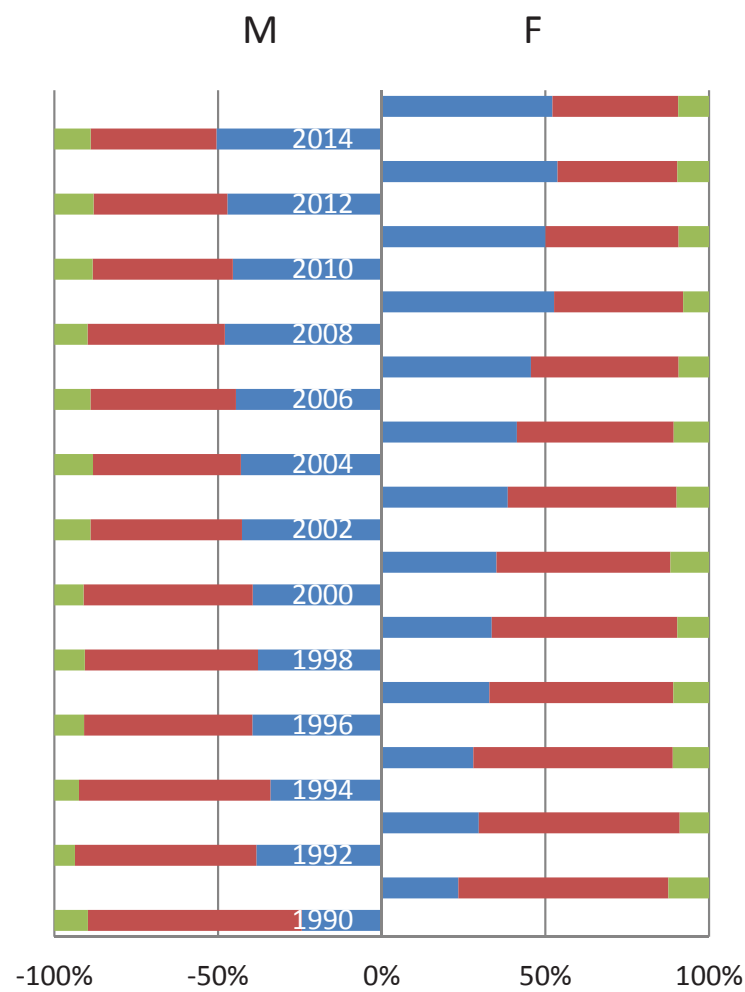

- Good or very good

nedium

Bad or very bad

Figure 7. The dynamic of self-assessment of health by Estonian men and women from 1990 to 2014. Data: database of the National Institute for Health Development $\mathbf{t}$

The most spectacular effect is that the share of people, estimating their health as good or very good has increased from $23 \%$ in 1990 up to more than $50 \%$ in 2014. At the same time the share of people having bad health conditions has not changed very much, it is steadily about $10 \%$. The trends are quite similar in both sexes.

\section{Dynamics of self-assessment depending on age group}

Figure 8 presents the percentage of answers "health is good/very good" given in different age groups in different years. In general, all age groups show an improvement of assessments, but due to randomness, the trend is not equable - a situation that is common in surveys. The increase was most rapid in the age group of $25-34$ where at the beginning only $36 \%$ declared that their health was good, but finally (in 2014) the percentage of people having good health almost doubled. By absolute value, the increase of people having good 
health was the smallest in the most elderly age group - only $15 \%$, from $10 \%$ in 1990 to $25 \%$ in 2014.

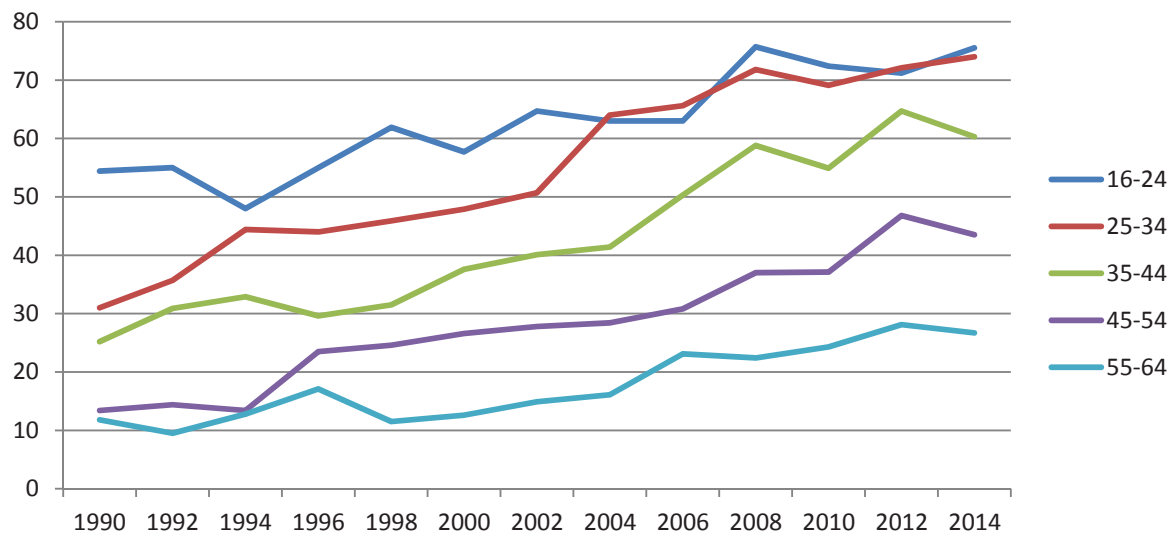

Figure 8. Dynamics of percentages of estimated good or very good health in different age groups during the period 1990-2014. Data: database of the National Institute for Health Development

\section{Impact of education and ethnicity on self-assessment of health}

Survey data of self-assessment, measured in a long time, confirm the impact of education and ethnicity on not only the declared situation at some fixed moment but also on its dynamics; see Figures 9 and 10.

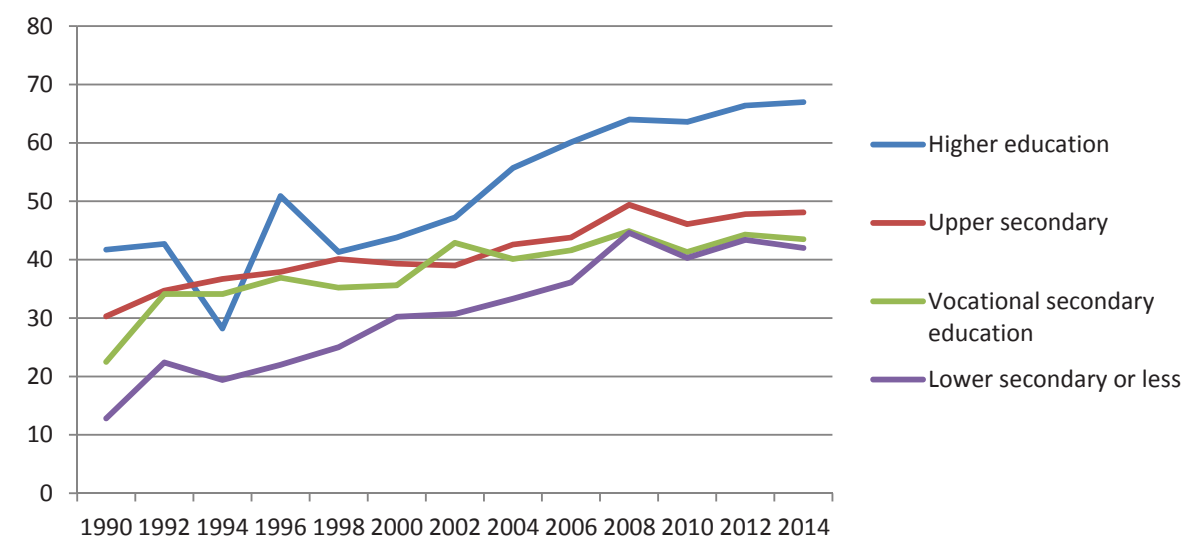

Figure 9. Dynamics of percentages of estimated good or very good health in different education groups during the period 1990-2014. Data: database of the National Institute for Health Development 
IIt is interesting that the increase in the percentage of people feeling that their health is good is bigger in the groups of higher but also the lowest education and stays lower in the groups of middle education level.

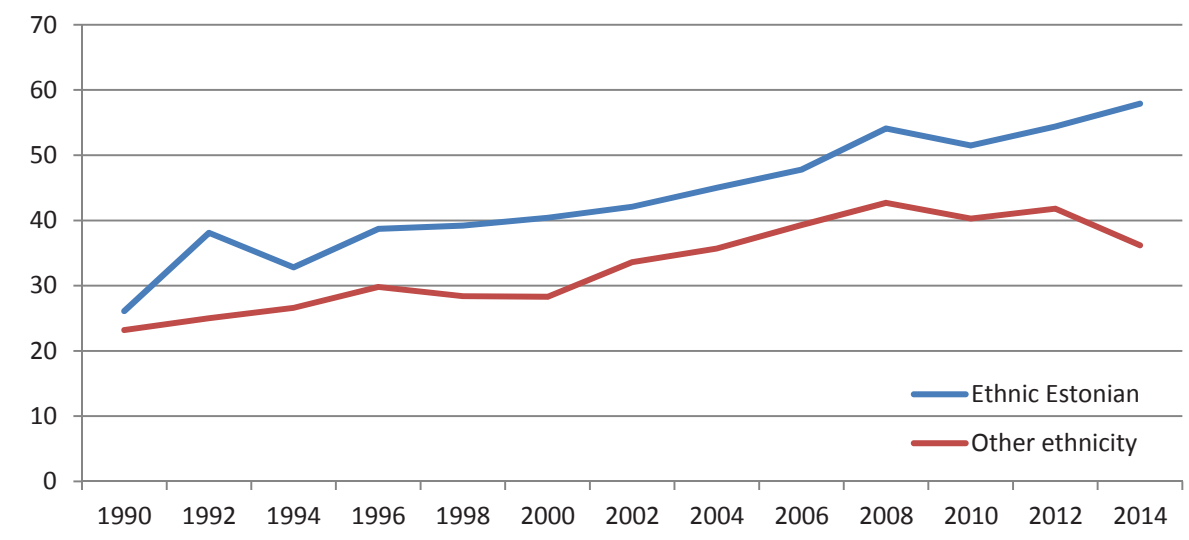

Figure 10. Dynamics of percentages of estimated good or very good health in different ethnic groups during the period 1990-2014. Data: database of the National Institute for Health Development

The impact of ethnicity on self-estimated health is rather strong, but the last step - decrease of percentage in the group of non-Estonians - seems to be a random effect due to the small sample size of this population group.

\section{CONCLUSION}

Statistical analysis shows that both objective and subjective data confirm that the general health situation of the Estonian population is steadily improving. From all characteristics used in the paper, life table and life expectancy are objective, using mortality statistics that is precise and of high quality in Estonia. The increase of life expectancy during the last twelve years is remarkable.

Disability-free life expectancy has been calculated using both objective data (life table) and subjective estimates of restrictions-free life. All other characteristics, either gathered during the census or in surveys, are subjective. Still the concordance between objective and subjective indicators is quite good and, by combining them, it can be confirmed that the health situation of the Estonian population is improving, but during $27-30 \%$ of their life span, people have different health problems. 
Health depends on many factors: the difference between men and women is remarkable, in average women live about 8 years longer. The following tendencies also appear: the higher a person's education, the longer he/she lives; ethnic Estonians live longer and feel healthier than representatives of other ethnicities. The health situation is also different in different regions, being the best in the areas where the economic situation is better. People living in rural areas feel more restrictions to everyday life that can be caused by missing amenities in their living environment.

\section{ACKNOWLEDGEMENTS}

TThe research was partially supported by institutional research funding IUT34-5 of the Estonian Ministry of Education and Research.

\section{REFERENCES}

1. Database of the National Institute for Health Development, http://pxweb.tai.ee/esf/pxweb2008/dialog/statfile2.asp.

2. E-Health, http://www.e-tervis.ee/index.php/en

3. SHARE-Estonia, http://www.share-estonia.ee/

4. Statistics Estonia, http://www.stat.ee/

5. Tiit, Ene-Margit, 2011. Eesti rahvastik. Viis põlvkonda ja kümme loendust. Tallinn: Statistikaamet, 176 pp.

6. United Nations Millenium Development Goals Indicators, [http://mdgs.un.org/unsd /mdg/Default.aspx

\section{Address for correspondence:}

Ene-Margit Tiit

Institute of Mathematical Statistics

Faculty of Mathematics and Computer Science

University of Tartu, Tartu, Estonia

J. Liivi 2-513, 50409 Tartu, Estonia

E-mail:ene.tiit@ut.ee 